\title{
The influence of molecular weight on the properties of polyacetal/hydroxyapatite nanocomposites. Part 2. In vitro assessment
}

\author{
Kinga Pielichowska
}

Received: 10 April 2011 / Accepted: 1 November 2011 /Published online: 22 February 2012

(C) The Author(s) 2012. This article is published with open access at Springerlink.com

\begin{abstract}
A series of polyoxymethylene (POM)/hydroxyapatite (HAp) nanocomposites for long-term bone implants were prepared by melt processing using POM with different molecular weight. Bioactivity was examined by incubating the samples in simulated body fluid. Moreover, in vitro stability, wettability, thermal stability, and formaldehyde release process were investigated. Results of in vitro investigations show that an increase in HAp content in POM nanocomposites facilitates the formation of an apatite layer on the sample surface. There is no significant influence of HAp concentration on the contact angle values as revealed by wettability studies. Thermogravimetric analysis results indicate that with an increase in HAp content the thermal stability of POM matrix decreases significantly depending upon the POM molecular weight. Finally, it was found the amount of formaldehyde leached out of the samples during the incubation period depends on the HAp content: amounts in excess of $3 \mathrm{ppm}$ were emitted for the samples containing only $10 \%$ HAp.
\end{abstract}

Keywords Biological applications of polymers .

Biomaterials · Nanocomposites $\cdot$ Thermogravimetric analysis

\section{Introduction}

Polyoxymethylene (POM) belongs to the group of engineering thermoplastics with properties that include excellent

K. Pielichowska $(\triangle)$

Faculty of Materials Science and Ceramics,

Department of Biomaterials,

AGH University of Science and Technology,

Al. Mickiewicza 30,

30-059 Kraków, Poland

e-mail: kingapie@agh.edu.pl "metal-like" machining characteristics (high mechanical strength, excellent abrasion, fatigue resistance, moldability, etc.). POM has a long history of use in animal studies and as a long-term implant material in a variety of medical applications. These include cardiac valve prostheses (e.g., the BjörkShiley valve tilting-disk style prosthesis [1,2], dental implants [3], and prosthetics as well as orthopedic implants [4-7].

The use of POM (Delrin ${ }^{\circledR}$ ) in total hip prostheses was first suggested in the mid-1960s, and since 1970 Delrin acetal polymer has been used in the Christiansen total hip prosthesis and endoprosthesis. Up to the end of 1977, approximately 7,000 surgical procedures had been carried out with the prosthesis in the USA; POM components of the Christiansen prosthesis were implanted in about 20,000 patients worldwide in the 1970s and 1980s [8]. The prosthesis durability was assessed as high, i.e., prostheses removed in cases of inflection or loosening did not show wear on the articulating Delrin components. Furthermore, histological studies of the surrounding tissue show a benign tissue response similar to that seen around polyethylene implants. Hence, the Christiansen Delrin prosthesis has been recommended as a Class II device by the US Food and Drug Administration [9].

$\mathrm{POM}$ as a media-wetted component in a tissue-engineering bioreactor was applied by Penick et al. [10] who found that the use of POM appears to be innocuous, at least with respect to human mesenchymal stem cells (MSC)-based tissue engineering, even after machining and repeated autoclaving.

Vitral and co-workers [11] investigated the cellular viability and nitric oxide production by $\mathrm{J} 774$ macrophages with ceramic, polycarbonate, and POM brackets. Their conclusion was that in the bracket group there was no significant difference compared with the control group.

According to Kokubo and Takadama's definition of bioactivity, a bioactive material is a material on which bone-like 
hydroxyapatite (HAp) will form selectively after it is immersed in a serum-like solution [12]. However, HAp and $\beta$-tricalcium phosphate are difficult to shape in the complex forms required for bone treatment because of their hardness and brittleness. The concept of using bioactive HAp particles/modified polymer composites as implant materials for bone replacement was introduced by Bonfield in the early 1980s [13]. Since then, HAp-modified polymer-based biocomposites have been widely studied for bone tissue replacement. The polymer matrix provides the ductility and other associated properties that are required for hard tissue replacement materials $[14,15]$. The bioactivity of these composites is rendered by the bioactive component which, when implanted into the human body, interacts with the surrounding bone and, in some cases, even with the soft tissue. This occurs through a time-dependent modification of the surface, triggered by its implantation within the living bone. An ion exchange reaction between the bioactive implant and the surrounding body fluids results in the formation of a biologically active carbonate apatite (cHAp) layer on the implant that is chemically and crystallographically equivalent to the mineral phase of bone [16].

In this study nanosized HAp was introduced into the POM matrix to produce a new high-quality bioactive material for bone implants. Results of the bioactivity assessment, thermal stability, long-term stability, and formaldehyde release of POM/nano-HAp nanocomposites are presented.

\section{Experimental}

Materials and processing

Three commercial grades of POM copolymers T200, T300, and T411 (Tarnoform $\left.{ }^{\circledR}\right)(\mathrm{T} 2, \mathrm{~T} 3$, and T4, respectively), with
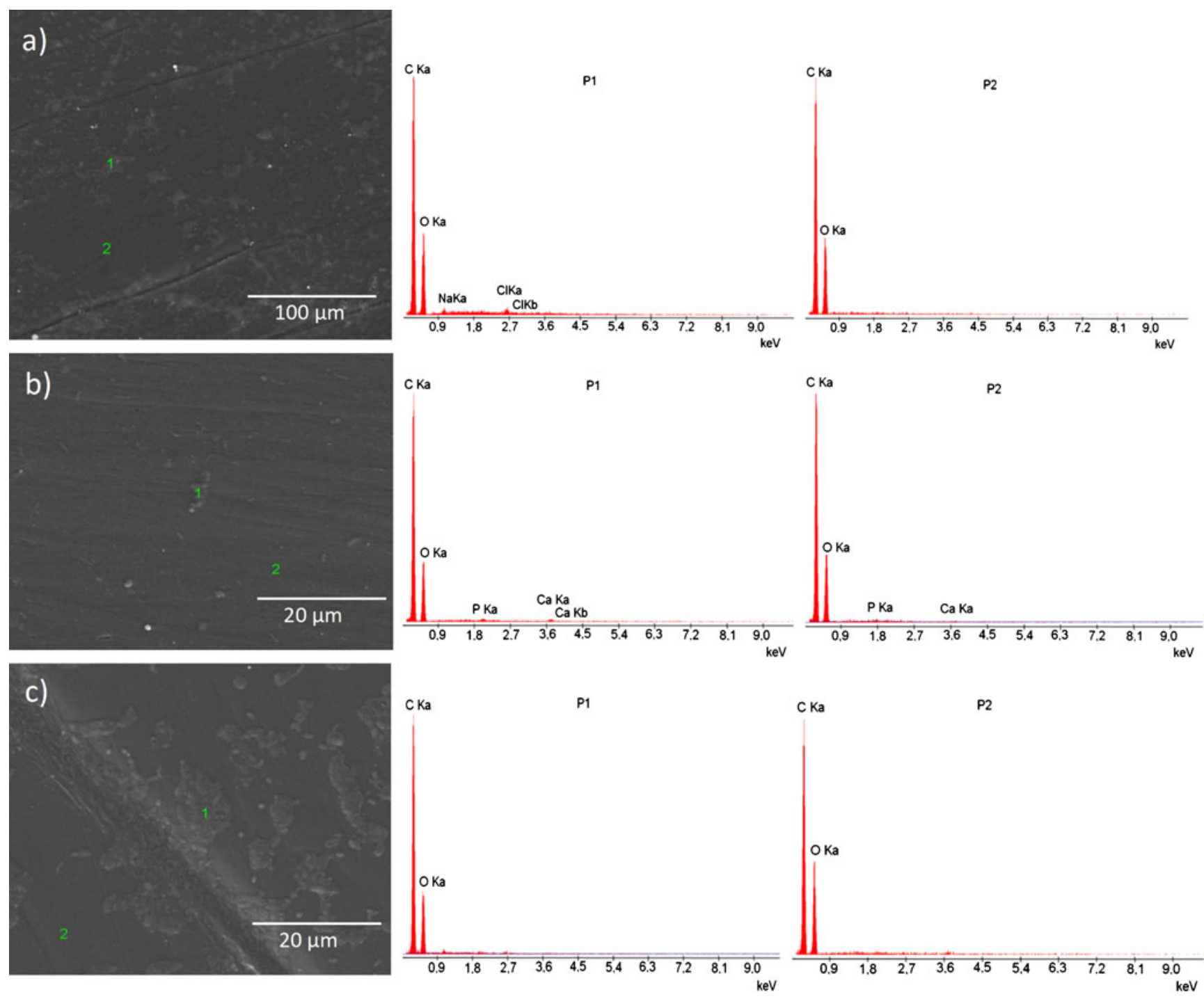

Fig. 1 SEM microphotographs (left) and EDX analysis (right) at two marked points ( 1 and 2) after 21 days of incubation in SBF: a T2, b T3, and c $\mathrm{T} 4$ 
melt flow rate (MFR 190/2.16, ISO 1133) of 2.5, 9.0, and $13 \mathrm{~g} / 10 \mathrm{~min}$, respectively, were acquired from Zaklady Azotowe w Tarnowie-Mościcach SA. Molecular weight characteristics of the POM copolymers are given elsewhere [17].

Hydroxyapatite $\mathrm{Ca}_{10}\left(\mathrm{PO}_{4}\right)_{6} \mathrm{OH}_{2}$ nanopowder with a nanoparticle size below $100 \mathrm{~nm}$ (99\% of particles) was produced by nGimat Co. (Atlanta, USA).

$\mathrm{POM}$ and POM/HAp nanocomposites were prepared by the melt processing method. Firstly, POM was air-dried, and then the POM and HAp were mechanically mixed $(0,0.5$, $1.0,2.5,5$, and $10.0 \% \mathrm{w} / \mathrm{w}$ of HAp) and extruded using a double-screw extruder (ThermoHaake PolyLab PTW 16/25) at a screw speed of $50 \mathrm{rpm}$. Specimens were prepared by using a DSM laboratory injection molding machine.
Characterization

POM/HAp nanocomposites specimens have been immersed in a simulated body fluid (SBF) at $37{ }^{\circ} \mathrm{C}$ for 21 days. After soaking, the specimens were removed from the SBF, gently rinsed with distilled water and dried [18]. After SBF immersion, the sample surface was examined by scanning electron microscopy (SEM) with a Nova Nano SEM 200, equipped with an energy dispersive X-ray analyzer (Edax), which was used to investigate the surface morphology of carbon-coated samples at the operating voltage of $5 \mathrm{kV}$.

Moreover, $\mathrm{POM}$ and $\mathrm{POM} / 10.0 \%$ HAp samples were incubated at $70{ }^{\circ} \mathrm{C}$ according to EN ISO 10993-13 for 41 weeks in Ringer fluid, made by Baxter Terpol Sp. z o.o.
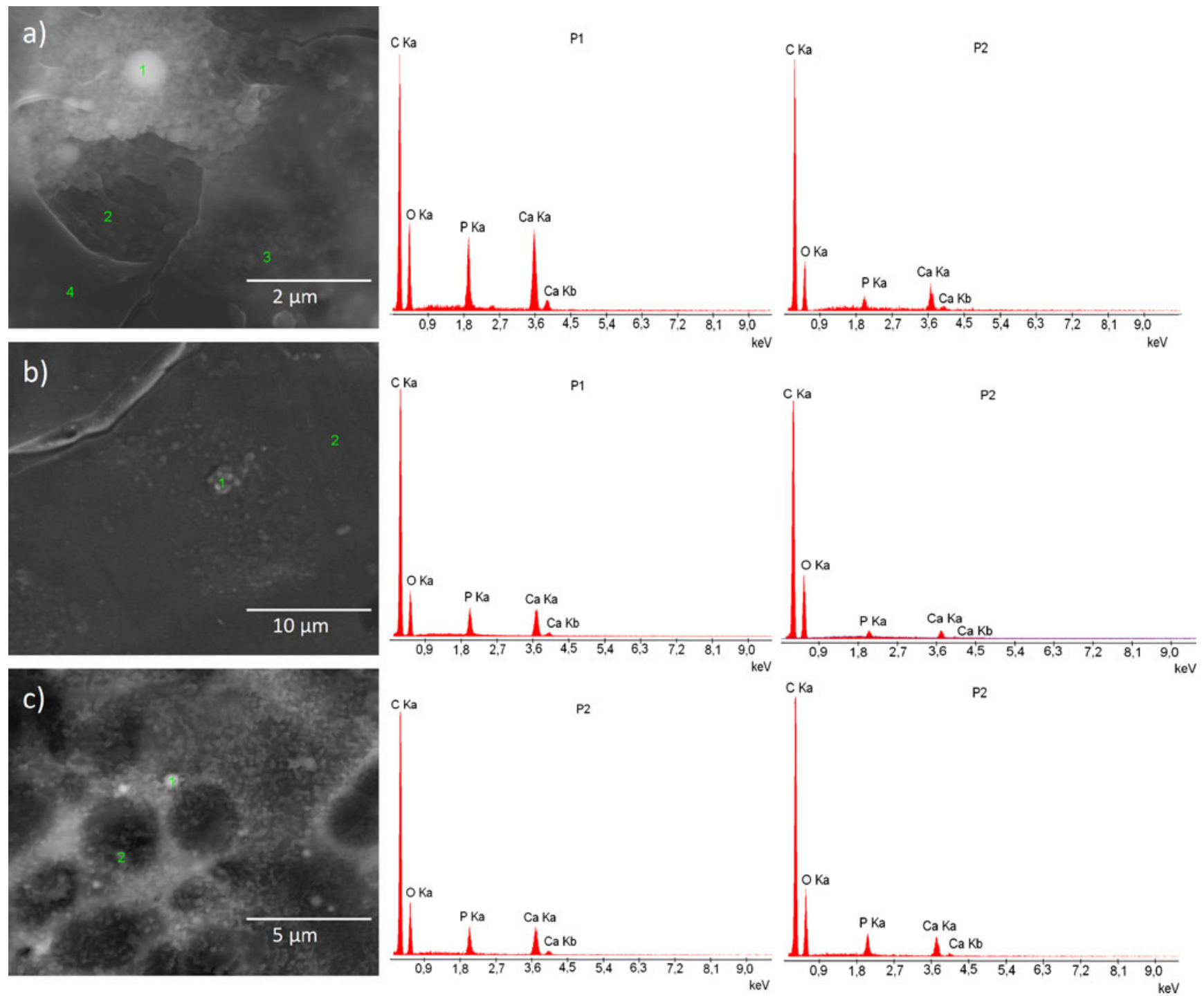

Fig. 2 SEM microphotographs (left) and EDX analysis (right) at two marked points (1 and 2) after 21 days of incubation in SBF: a T2/5\% HAp, b $\mathrm{T} 3 / 5 \%$ HAp, and $\mathbf{c}$ T $4 / 5 \%$ HAp 
(biological environment simulation) and distilled water. The $\mathrm{pH}$, conductivity, and mass change were measured during incubation.

Thermogravimetric (TG) analysis was performed using a Netzsch TG 209 thermal analyzer, operating in a dynamic mode at a heating rate of $10 \mathrm{~K} / \mathrm{min}$ under the following conditions: sample weight, ca. $5 \mathrm{mg}$; atmosphere, argon; open $\alpha-\mathrm{Al}_{2} \mathrm{O}_{3}$ pan.

The contact angles were measured by the sessile drop method using an automatic drop shape analysis system DSA 10 Mk2 (Kruss, Germany). Ultra high quality (UHQ) water droplets with a volume of $0.2 \mu \mathrm{L}$ were placed on each sample surface and the contact angles were obtained by averaging the results of ten measurements.

The formaldehyde release during incubation was analyzed using Schiff's reagent. Samples were incubated in sealed pans in distilled water with a sample mass/water volume ratio $1: 10$ at $37{ }^{\circ} \mathrm{C}$ for 1 week. After every $24 \mathrm{~h}$ the water was removed from the sample pan and moved to the test tube; fresh water was then introduced into the sample pan (dynamic incubation). Schiff's reagent was added to the test tube with water and the change in color was monitored.

\section{Results and discussion}

In vitro evaluations

Distinctive properties of bioactive materials are their ability to form an HAp layer on their surface in body fluid and bond directly to bone tissue. HAp and its composites are widely used owing to their good biocompatibility and osteointegrative properties; HAp reacts with physiological fluids and forms tenacious bonds to hard and soft tissues through cellular activity [19].

In vitro evaluation is a fundamental procedure to assess the bioactivity and biostability of a synthetic material [15]. Hence, POM, POM/0.5\% HAp, and POM/5.0\% HAp were immersed in SBF for 21 days. The samples' surface morphology was analyzed by SEM-EDX (Figs. 1 and 2).

SEM microphotographs and EDX analysis show the deposition of new particles and suggest the formation of an apatite-like compound on the surface of the composites after being soaked in SBF. EDX analysis for all the samples display two large peaks from carbon and oxygen which are the main constituents of POM chains. Moreover, for all pure POM copolymers very poor apatite formation
Fig. 3 Wetting angle for the investigated samples

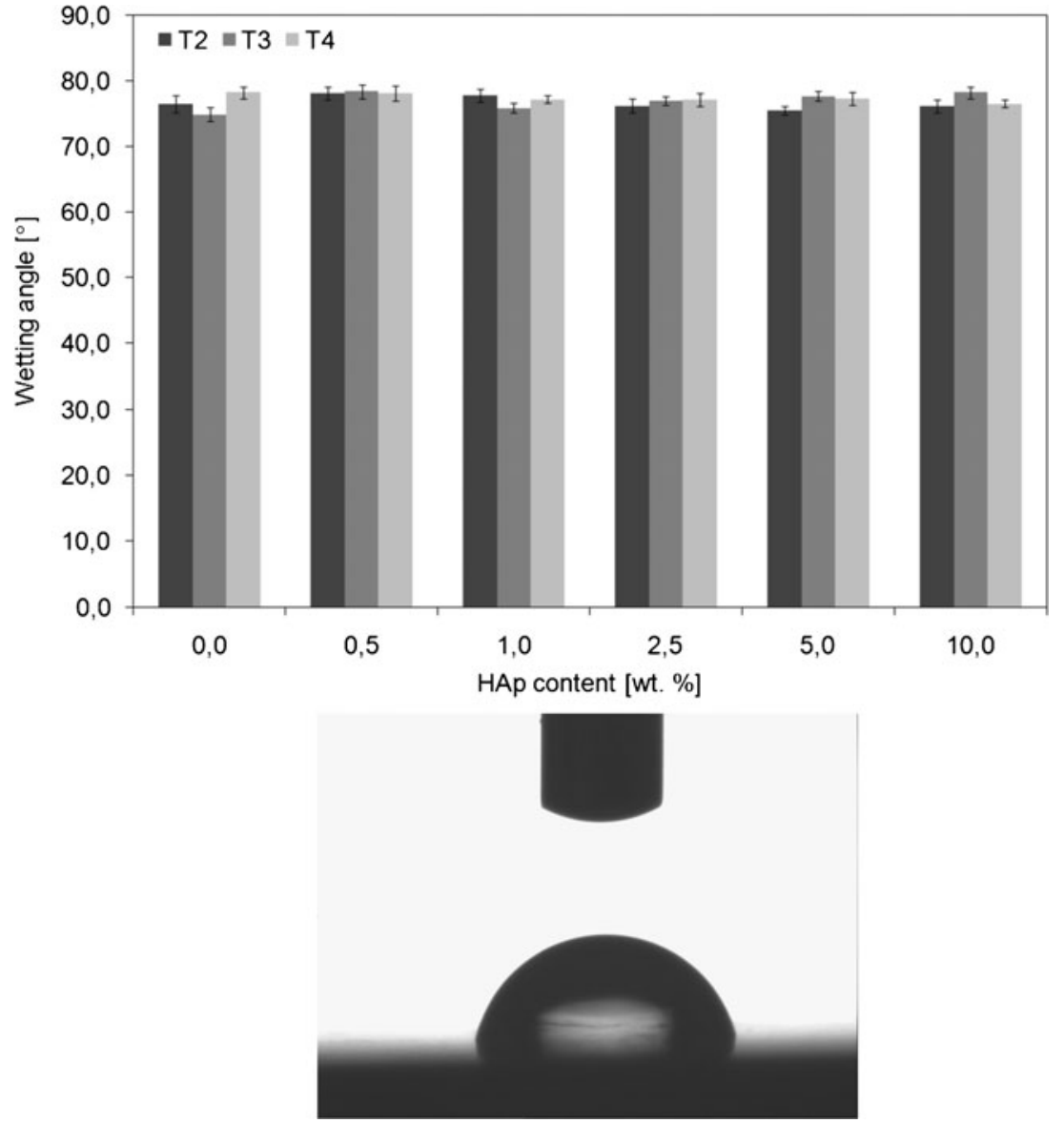


was found with very small changes in EDX analysis. In contrast, for samples with 5.0\% HAp content, an apatitelike structure was formed on the surface as confirmed by EDX analysis. Two large peaks from carbon and oxygen atoms are still present; however, peaks from calcium and phosphorus do occur. A similar effect was also observed for other polymer/HAp nanocomposites as well, e.g., Kong and co-workers [20] investigated chitosan/HAp nanocomposites and revealed that the addition of nanoHAp led to better biomineral activity than chitosan scaffolds. They showed that in the composite scaffolds, nano-HAp particles provided nuclei in the mineralization
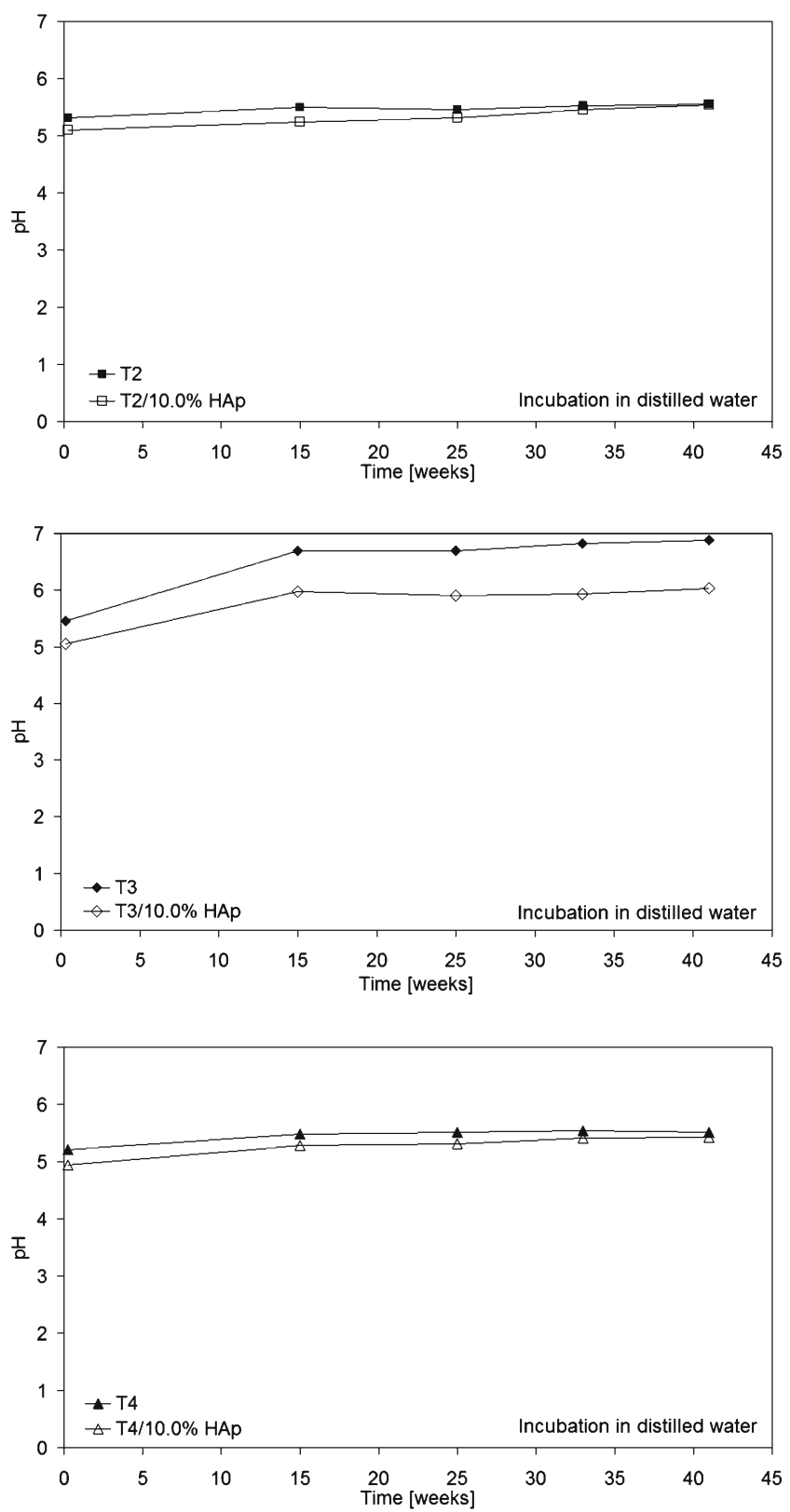

Fig. $4 \mathrm{pH}$ changes of distilled water as a function of incubation time of POM and POM/10.0\% HAp samples (for T2, T3, and T4, respectively) process. As a result more apatite formed on the composite scaffolds than on the chitosan scaffolds.

Interestingly, polymer functional groups may play a role in the nucleation and deposition of apatite. For example, the presence of the functional groups such as $-\mathrm{COOH}$ and $-\mathrm{OH}$ led to increased nucleation rates. Other properties that may affect apatite nucleation and growth are polymer crystallinity, hydrophobicity/hydrophilicity of the surface, pore size, shape, and interconnectivity [21,22].

The largest peak intensity in the EDX data was observed for sample T2. This effect can be attributed to T2 having the lowest degree of crystallinity among the studied samples
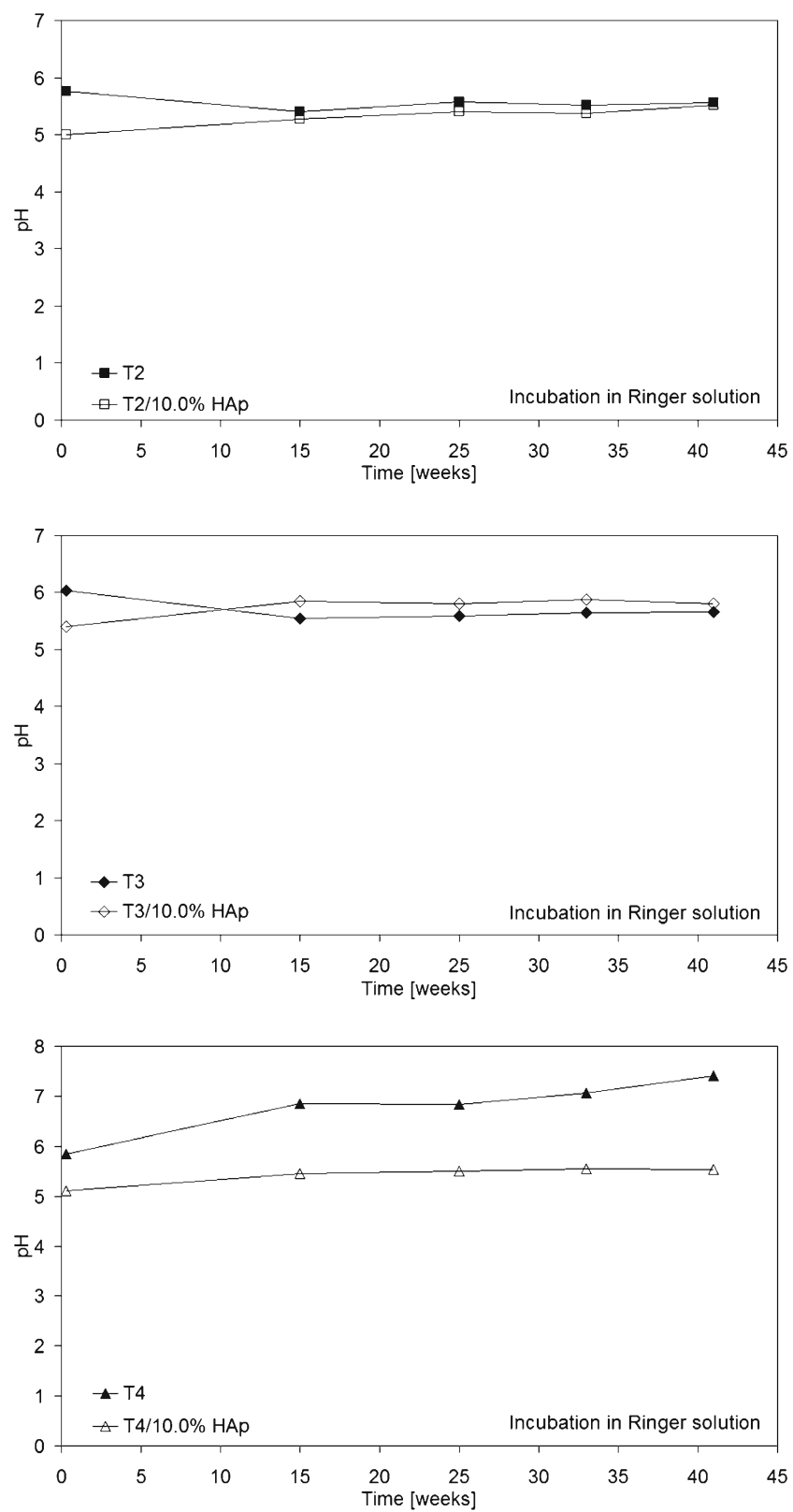

Fig. $5 \mathrm{pH}$ changes of Ringer solution as a function of incubation time of POM and POM/10.0\% HAp samples (for T2, T3, and T4, respectively) 
[17]. The presence of larger amounts of defects and numerous amorphous regions in this sample provided additional sites for the apatite nucleation process.

The water contact angle provides an indication of surface hydrophilicity by measuring how much a droplet of water spreads on a surface; the lower the contact angle, the more hydrophilic the surface is. As a surface becomes more oxidized, or has more ionizable groups, hydrogen bonding with the water becomes more facile and the droplet spreads along the hydrophilic surface, resulting in a lower contact angle [23]. Results for contact angle measurements for POM and POM/HAp nanocomposites are presented in Fig. 3.

From Fig. 3 it can be seen that there is no significant influence of HAp concentration on contact angle values. A similar effect was also observed by Wang et al. for polycaprolactone (PCL)/HAp nanocomposites [24]. PCL/HAp nanocomposites demonstrated only a weak increase in the water contact angle, meaning that the nanocomposites did not become more hydrophilic when HAp nanoparticles were added. Moreover, it has been reported that a greater crystallinity can lead to a higher energy surface and lower contact angles [25]. Elsewhere, Yasuda and co-workers [26] have shown that PA-6 specimens with a wide range of bulk crystalline fractions $(X \mathrm{c}=0.25$ to 0.46$)$ give similar contact angles. This would indicate that as the polymer surfaces were covered with a thin skin, it seems unlikely that bulk crystallinity influenced the contact angles or hysteresis. As can be seen in Fig. 3 for pure POM very little change of contact angle occurs with a decrease of molecular weight and degree of crystallinity; $X \mathrm{c}$ (by DSC method) $=0.44$, 0.48 , and 0.51 for $\mathrm{T} 2, \mathrm{~T} 3$, and $\mathrm{T} 4$, respectively [17].

In vitro stability of POM and POM/10.0\% HAp samples was determined on the basis of $\mathrm{pH}$ variation of distilled water and Ringer solution, and mass changes of the samples during incubation at $70{ }^{\circ} \mathrm{C}$ for 41 weeks (according to EN ISO 10933, an accelerated degradation test as a screening method). Incubation time was increased to 9 months (for the accelerated method the incubation time is usually 60 days)
Fig. 6 TG and differential thermogravimetric (DTG) curves of pure T2 and T2/HAp nanocomposites
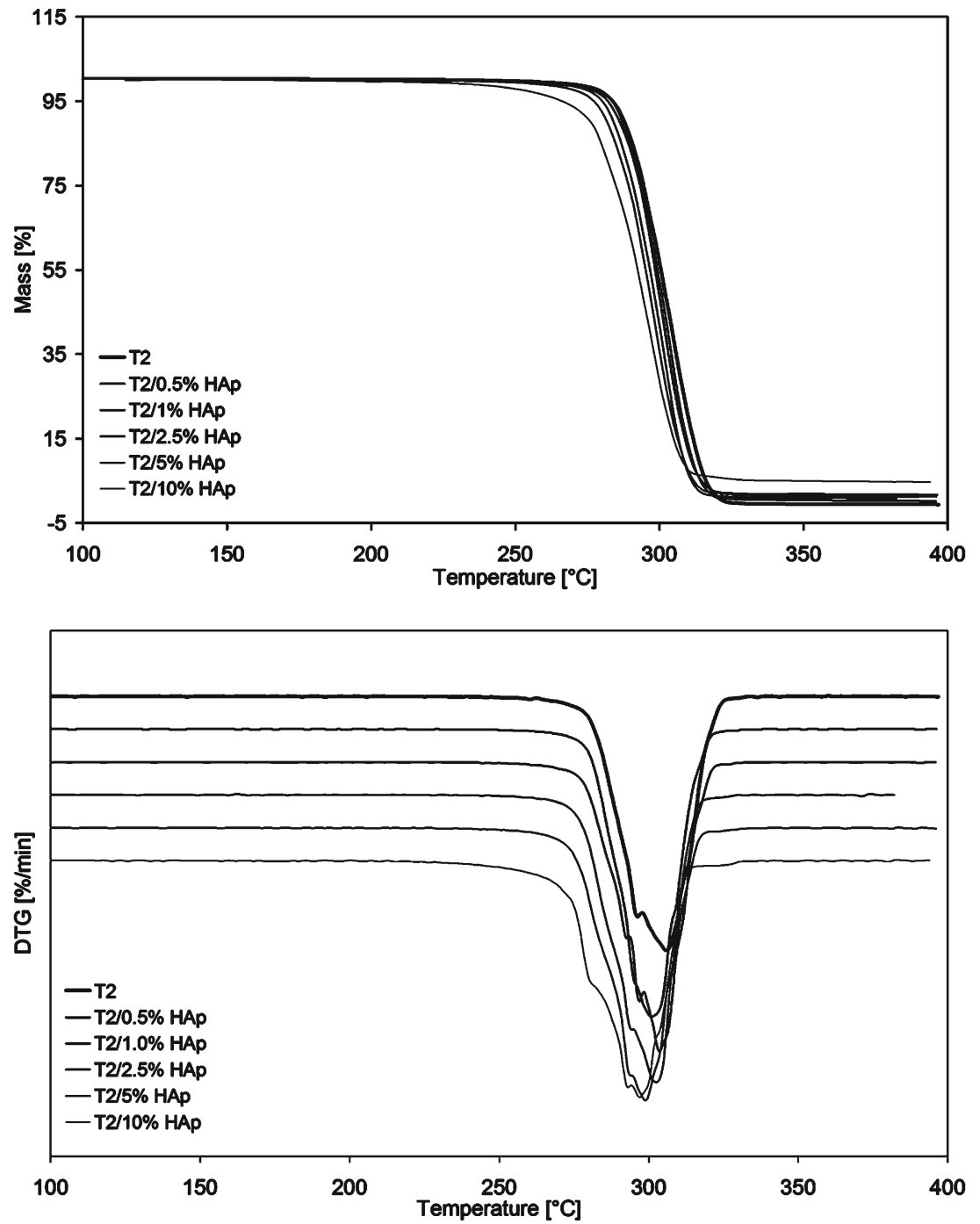
to investigate the long-term stability of POM at elevated temperature (Figs. 4 and 5).

Figures 5 and 6 show the lack of significant $\mathrm{pH}$ changes both in water and Ringer solution during incubation period for POM-based materials. There was also no significant difference in the in vitro behavior between pure POM and $\mathrm{POM} / 10.0 \%$ HAp nanocomposites. Moreover, the mass of the samples did not change after incubation. The obtained results confirm the very good in vitro stability of POM and POM/HAp nanocomposite samples.

Thermal stability and formaldehyde release

Apart from the numerous advantages of POM in terms of mechanical properties and chemical stability, polyacetal has a propensity to depolymerize (or "unzip") into formaldehyde $\left(\mathrm{CH}_{2} \mathrm{O}\right)$ under specific circumstances. Since the main chain of POM is composed of $-\mathrm{CH}_{2}-\mathrm{O}-$ bonds, the methylene-oxygen bonds are easy to break under heat and oxygen; they are also sensitive towards bases and acids, and this breakage results in a continuous depolymerization reaction yielding formaldehyde. Commercial acetal copolymers are typically produced by cationic polymerization of 1,3,5-trioxane and a cyclic ether such as ethylene oxide, 1,3-dioxolane, or 1,3dioxepane. Acetal copolymer resin has greater stability but reduced crystallinity as a result of carbon-carbon bonded groups interspersed in its polymer chain [27]. The formaldehyde and formic acid formed thorough oxidation of formaldehyde can accelerate the depolymerization reaction; this process is usually called the zipper mechanism [28].

Thermal stability characteristics of POM and POM/HAp nanocomposites, prepared in the course of this work, are shown in Figs. 6, 7, and 8 and Table 1.

Analysis of TG results indicates that, generally, with an increase in HAp content the thermal stability of POM matrix decreases significantly. It should be noted that the difference between the thermal stability of pure POM and POM/10.0\% HAp is ca. $30^{\circ} \mathrm{C}$ for $\mathrm{T} 2$ and $\mathrm{T} 3$ copolymers, whereas for $\mathrm{T} 4$ copolymer the difference in thermal stability is ca. $60{ }^{\circ} \mathrm{C}$. For T2 and T3 copolymers the thermal stability slightly
Fig. 7 TG and DTG curves of pure $\mathrm{T} 3$ and $\mathrm{T} 3 / \mathrm{HAp}$ nanocomposites
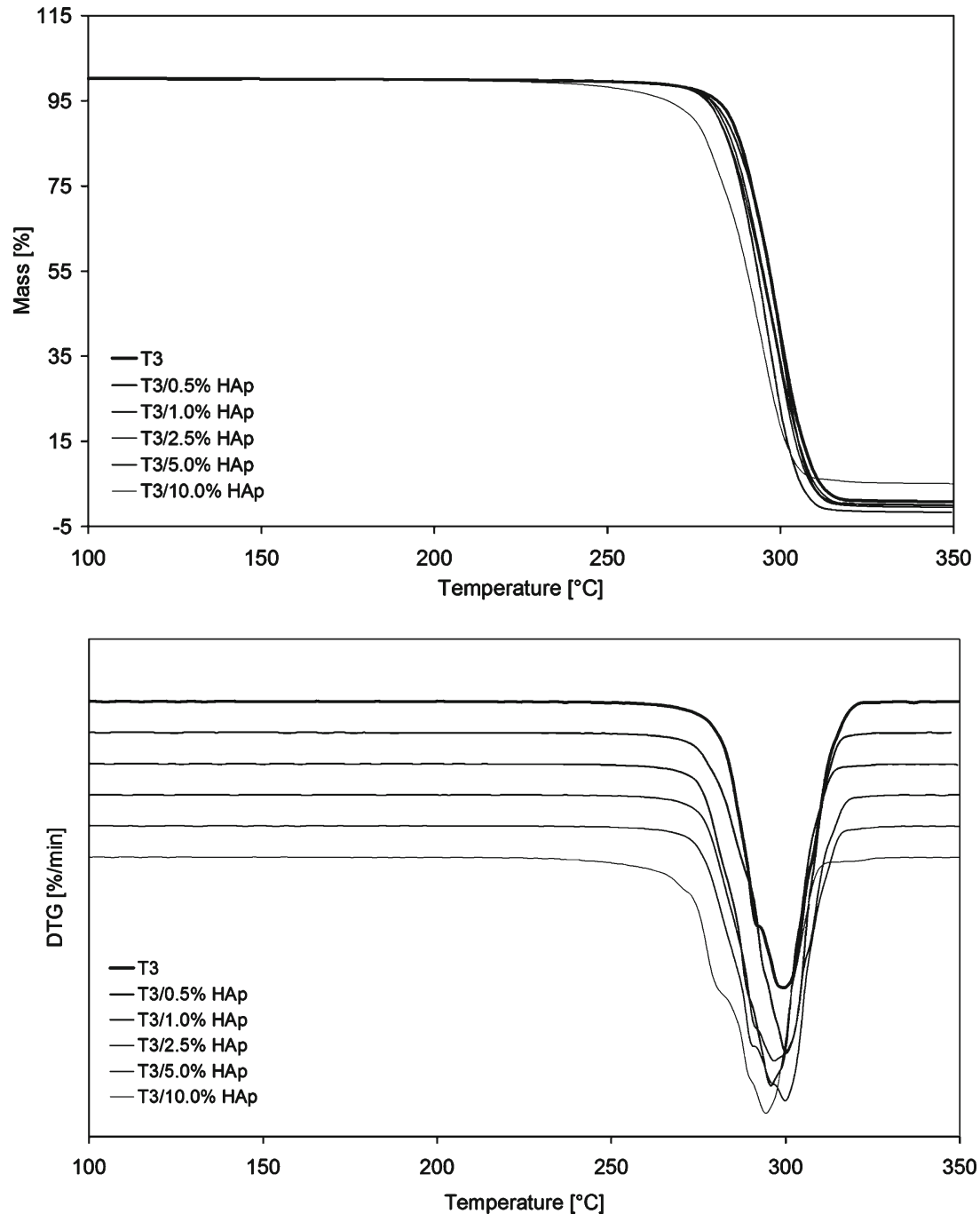
Fig. 8 TG and DTG curves of pure $\mathrm{T} 4$ and T4/HAp nanocomposites
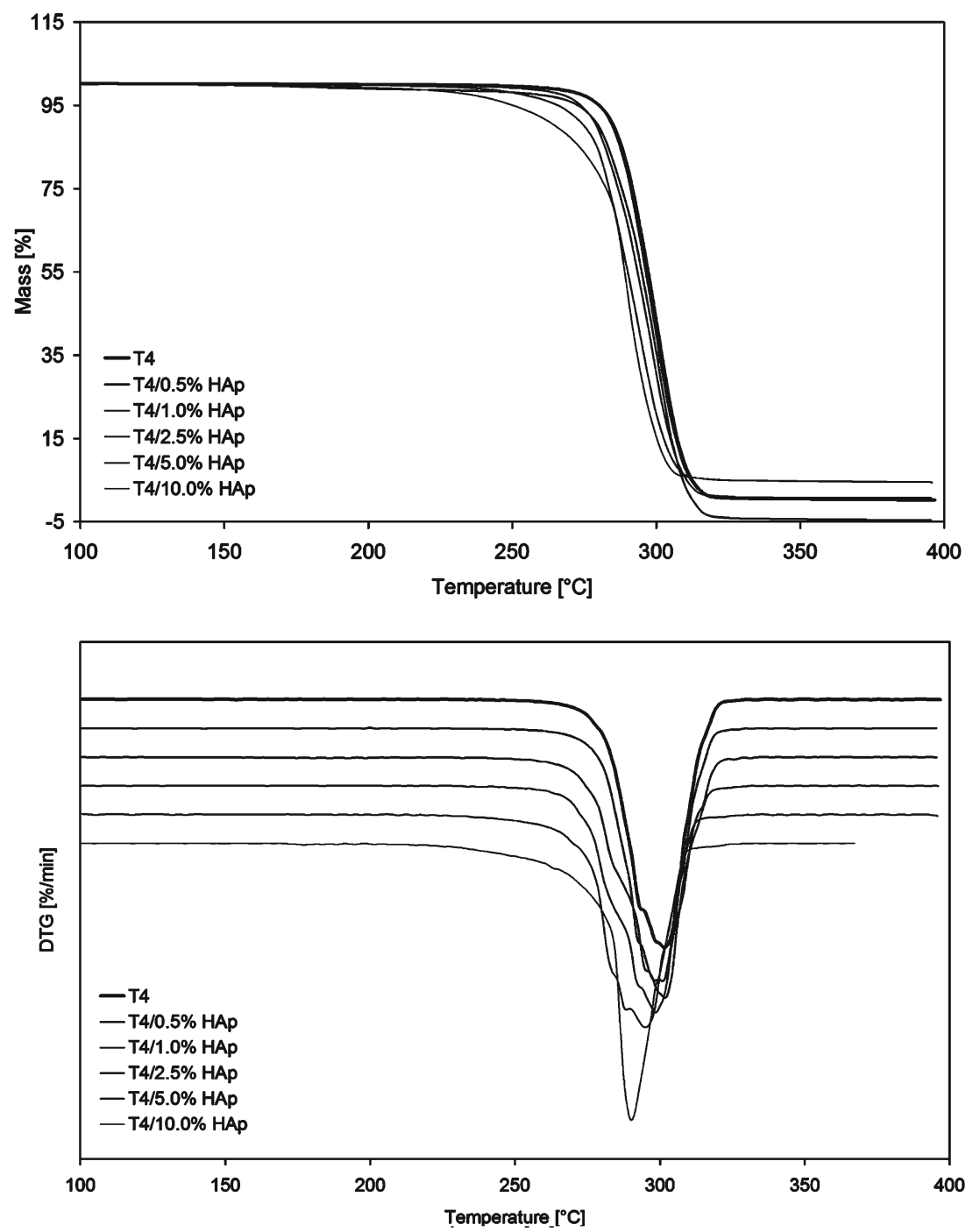

decreases with HAp content up to $5 \%$ and for the POM/ $10.0 \%$ HAp sample the thermal stability decreases rather sharply. For T4 copolymer the thermal stability decreases more rapidly with HAp content. Generally, the POM thermal stability decreases with a decrease of molecular weight: this effect can be attributed to the higher concentration of end groups in the POM matrix with low molecular weight (especially in T4 copolymer). It is understood that POM degradation is initiated either by bond dissociation at the chain end ( $-\mathrm{OH}$ groups), or by random main-chain scission for the end-capped polymer followed by unzipping [29, 30]. If the hydroxylic groups of POM are not blocked, rapid depolymerization takes place at moderate temperatures by a zipper mechanism yielding the monomer again [31]. Moreover, the reason for the lower thermal stability of POM/HAp nanocomposites is also the high sensitivity of the POM main chain to attack by base under heating. HAp with general formula $\left[\mathrm{Ca}_{10}\left(\mathrm{PO}_{4}\right)_{6}(\mathrm{OH})_{2}\right]$ can be also presented as $3 \mathrm{Ca}_{3}\left(\mathrm{PO}_{4}\right)_{2} \cdot \mathrm{Ca}(\mathrm{OH})_{2}-\mathrm{a}$ structure that contains calcium hydroxide. Besides, nanosized HAp particles with a very large surface area are more reactive at elevated temperature than micro-sized HAp.

An important issue with the application of POM as a bone implant material is associated with leaching of residual formaldehyde or that formed during polymer decomposition during incubation in different fluids as well as after implantation into the living body. For example, commercial POM (Delrin ${ }^{\circledR}$ ) contains 97\% POM polymer, 3\% stabilizer, and less than $0.005 \%$ of free formaldehyde, according to the relevant DuPont material safety data sheet. Because of the toxicity of formaldehyde it is necessary to know if formaldehyde is released, and, if so, what the level of emission is.

To detect the presence of formaldehyde in the filtrate from incubation of POM samples in distilled water Schiff's reagent (a fuchsin-aldehyde reagent) was used. The results are shown in Fig. 9: when the (colorless) reagent reacts with an aldehyde $\left(\mathrm{CH}_{2} \mathrm{O}\right)$, a change in the double bond configuration and hence in color occurs, which varies from magenta to deep purple. The purple color develops at a rate roughly related to the concentration of $\mathrm{CH}_{2} \mathrm{O}$ and the detection levels 
Table 1 TG results for POM and POM/HAp nanocomposites

\begin{tabular}{lllllllll}
\hline Sample & $\begin{array}{l}T_{1 \%} \\
\left({ }^{\circ} \mathrm{C}\right)\end{array}$ & $\begin{array}{l}T_{3 \%} \\
\left({ }^{\circ} \mathrm{C}\right)\end{array}$ & $\begin{array}{l}T_{5 \%} \\
\left({ }^{\circ} \mathrm{C}\right)\end{array}$ & $\begin{array}{l}T_{10 \%} \\
\left({ }^{\circ} \mathrm{C}\right)\end{array}$ & $\begin{array}{l}T_{20 \%} \\
\left({ }^{\circ} \mathrm{C}\right)\end{array}$ & $\begin{array}{l}T_{50 \%} \\
\left({ }^{\circ} \mathrm{C}\right)\end{array}$ & $\begin{array}{l}T_{\text {DTGmax }} \\
\left({ }^{\circ} \mathrm{C}\right)\end{array}$ & $\begin{array}{l}\text { Char residue at } \\
400\end{array}$ \\
\hline T2 $(\%)$
\end{tabular}

are between 3 and $5 \mathrm{ppm}$. No reaction is seen if the concentration of $\mathrm{CH}_{2} \mathrm{O}$ is less than 3 ppm [32]. Figure 9 shows test tubes with filtrate after 5 days of incubation of the selected samples to which Schiff's reagent has been added.

Only for samples with $10 \%$ HAp content can weak pink color be observed, but it should be noted that with an increase of POM molecular weight $(\mathrm{T} 2>\mathrm{T} 3>\mathrm{T} 4)$ the intensity of the pink color in decreases. This can be related to the lower thermal stability of POM in POM/10.0\% HAp nanocomposites and additionally the lowest thermal stability of $\mathrm{T} 4$ copolymer. Moreover, during tests with Schiff's reagent it was revealed that the intensity of pink color decreases with time of dynamic incubation: this suggests that occluded formaldehyde is released first, after which the emission declines. During the melt processing of samples with $10 \%$ of HAp POM undergoes some thermal degradation and formaldehyde may be occluded in the
Fig. 9 Chemical reaction of Schiff's reagent with formaldehyde (a) and resultant color changes in test tubes containing filtrates from $\mathrm{POM}$ and POM/HAp nanocomposites after addition of Schiff's reagent (after 5 days of incubation) (b)
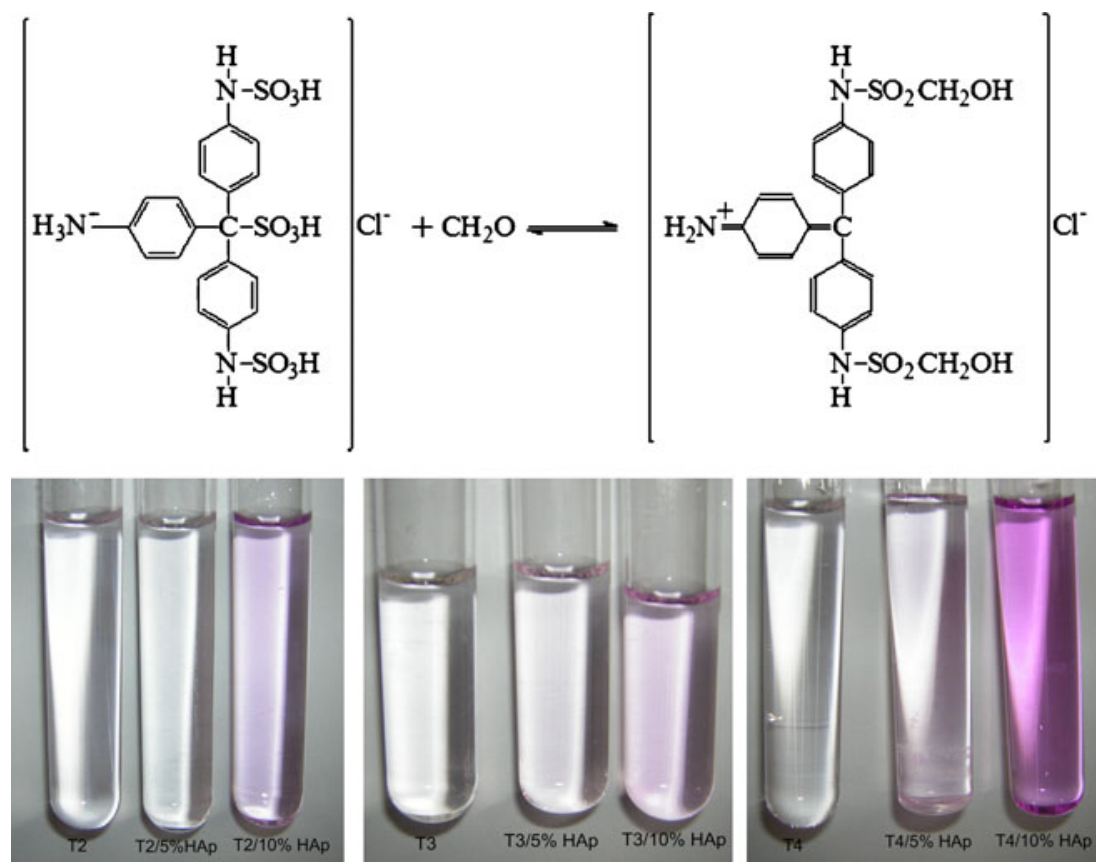
extruded material. These results confirm observations from the preparation stage when some odor of formaldehyde was perceptible. However, for further application of POM-based materials as implants the most important conclusion is that for pure $\mathrm{POM}$ and for bioactive nanocomposite $\mathrm{POM} / 5.0 \%$ HAp there is no visible pink color in test tubes, which means that the concentration of formaldehyde in the filtrates is below $3 \mathrm{ppm}$. This value is generally accepted for medical applications.

\section{Conclusions}

Novel POM/HAp nanocomposites for long-term bone implants were prepared by melt processing. Very poor apatite formation was found for all pure POM copolymers, whereas sample surfaces uniformly covered with apatite-like structures (confirmed by EDX analysis) were observed for copolymers with 5.0\% HAp content. The obtained results confirm the bioactivity of the investigated POM/HAp nanocomposites. In vitro evaluation proves that $\mathrm{POM}$ and $\mathrm{POM} / \mathrm{HAp}$ nanocomposites have good stability in distilled water and Ringer solution. Analysis of TG results indicates that, generally, the thermal stability of the POM matrix decreases significantly with the increase in HAp content; however, all investigated samples except POM/10.0\% HAp were stable enough to be molded by melt processing. Moreover, it was found that during the incubation period the amount of formaldehyde leaching out the samples depended upon the HAp content. It should be noted that the amount of leached formaldehyde also depends on the POM molecular weight: with an increase of POM molecular weight, the formaldehyde amount decreases. However, for further application of POM-based materials as implants the most important conclusion is that for pure POM and for bioactive nanocomposite POM $/ 5.0 \% \mathrm{HAp}$ there is no visible pink color in test tubes, signifying that the concentration of formaldehyde in the filtrates is below $3 \mathrm{ppm}$. This value is generally accepted for medical applications.

Acknowledgments The author is grateful to the Polish Ministry of Science and Higher Education for financial support under the grant No. PBZ/MEiN/01/2006/15.

Open Access This article is distributed under the terms of the Creative Commons Attribution Noncommercial License which permits any noncommercial use, distribution, and reproduction in any medium, provided the original author(s) and source are credited.

\section{References}

1. Björk VO (1972) Scand J Thorac Cardiovasc Surg 6:103

2. Björk VO (1969) Scand J Thorac Cardiovasc Surg 3:1

3. MacAfee KA, Quinn PD (1992) J Craniofac Surg 3:160

4. Fister JS, Memoli VA, Galante JO, Rostoker W, Urban RM (1985) J Biomed Mater Res 19:519

5. Brown SA, Mayor MB (1978) J Biomed Mater Res 12:67

6. Buch F, Albrektsson T, Herbst E (1985) Scand J Plast Reconstr Surg 19:223

7. Havelin LI, Gjerdet NR, Lunde OD, Rait M, Sudmann E (1986) Acta Orthop Scand 57:419

8. Dumbleton JH (1981) POM/metal joint prostheses. In: Dumbleton JH (ed) Tribology of natural and artificial joints. Elsevier, Amsterdam

9. Dumbleton JH (1979) Delrin as a material for joint prosthesis - a review. In: Syrett BC, Acharya A (eds) Corrosion and degradation of implant materials, ASTM special technical publication. American Society for Testing and Materials, Philadelphia

10. Penick KJ, Solchaga LA, Berilla JA, Welter JF (2005) J Biomed Mater Res 75A:168

11. de Andrade Vitral JC, Fraga MR, Souza MA, Ferreira AP, Vitral R (2010) Am J Orthod Dentofacial Orthop 137:247

12. Bohner M, Lemaitre J (2009) Biomaterials 30:2175

13. Bonfield W, Grynpas MD, Tully AE et al (1981) Biomaterials 2:185

14. Wang M (2003) Biomaterials 24:2133

15. Pielichowska K, Błażewicz S (2010) Adv Polym Sci 232:97

16. Liang W, Rahaman MN, Day DE et al (2008) J Non-Cryst Solids 354:1690

17. Pielichowska K (2011) J Polym Res. doi:10.1007/s10965-011-9775-3

18. Kokubo T, Takadama H (2006) Biomaterials 27:2907

19. Yoganand P, Selvarajan V, Rouabhia M, Cannillo V, Sola A (2010) J Phys Conf Series 208:12099

20. Kong L, Gao Y, Lu G, Gong Y, Zhao N, Zhang X (2006) Eur Polym J 42:3171

21. Smith O, Liu XH, Smith LA, Ma PX (2009) WIREs Nanomed Nanobiotech 1:226

22. Zhang R, Ma PX (2004) Macromol Biosci 4:100

23. Goddard JM, Hotchkiss JH (2007) Prog Polym Sci 32:698

24. Wang S, Kempen DHR, Yaszemski MJ, Lu L (2009) Biomaterials 30:3359

25. Wu S (1982) Polymer interface and adhesion. Marcel Dekker, New York

26. Yasuda T, Okuno T, Yoshida K, Yasuda H (1988) J Polym Sci B Polym Phys 26:1781

27. Lüftl S, Archodoulaki VM, Seidler S (2006) Polym Degrad Stab 91:464

28. Shi J, Jing B, Zou X, Luo H, Dai W (2009) J Mater Sci 44:1251

29. Hasegawa S, Takeshita S, Yoshii F, Sasaki T, Makuuchi K, Nishimoto S (2000) Polymer 41:111

30. Archodoulaki M, Liiftl S, Seidler S (2004) Polym Degrad Stab $86: 75$

31. Ramirez NV, Sanchez-Soto M, Illescas S, Gordillo A (2009) Polym Plastics Technol Eng 48:470

32. Kusy RP, Whitley JQ (2005) Am J Orthod Dentofacial Orthop $127: 420$ 